\title{
LA TRANSICIÓN DE LA EDUCACIÓN MEDIA A LA EDUCACIÓN SUPERIOR
}

Hugo Montes* 


\section{RESUMEN}

El tema es abordado desde tres ángulos diferentes a la vez que complementarios, a saber, el psicológico, el de la orientación vocacional y el de la preparación intelectual.

En el primero se hace notar la desazón con que los jóvenes dejan la enseñanza media, en la cual de ordinario recibieron protección y calor humano, y dan el paso a instituciones mayores que les son desconocidas y relativamente ajenas. Luego se señala la general desorientación vocacional con que muchos alumnos egresan de la educación media y, en fin, los riesgos de una enseñanza enciclopedista y recargada de contenidos que en parte explica la anterior desorientación e impide la formación adecuada de la mente y de la persona misma del educando.

En todos los planos se sugieren algunas medidas, tanto para la media cuanto para los planteles de educación superior, que podrían si no remediar del todo, al menos paliar las deficiencias y riesgos indicados.

\section{ABSTRACT}

The issue described in the title is addressed from three different but supplementary points of view: from the psychological perspective, from the viewpoint of vocational guidance, and from the standpoint of intellectual preparation.

The psychological perspective addresses the insecurity that plagues young people upon completing secondary education -leaving a place where they regularly receive protection and human warmth- and moving on to larger, and relatively foreign institutions. The paper then describes the general vocational disorientation that affects many students when they leave secondary education and the risks posed by an education based on encyclopedic knowledge, loaded with contents, which partially accounts for their disorientation and which prevents students from developing adequately both mentally and as individuals.

Suggestions are made for all three levels, for secondary education as well as for higher education and, although these instances cannot remedy the problem entirely, they should at least be able to lessen the deficiencies and risks described in the paper. 


\section{LA TRANSICIÓN DE LA EDUCACIÓN MEDIA A LA EDUCACIÓN SUPERIOR}

\section{ASPECTOS PSICOLÓGICOS}

Ocho años de educación básica y cuatro de media ocurren a menudo en un mismo establecimiento y con los mismos compañeros. Ello permite el nacimiento entre los alumnos de vínculos de amistad, compañerismo, confianza en uno mismo y conocimiento recíproco. Son años de una vida organizada por la dirección de la escuela o del liceo, de modo que estudio, recreación y actividades extraprogramáticas se dan en forma equilibrada y provechosa. Los padres conocen y aceptan el sistema, y esta convergencia entre el establecimiento educacional y la familia facilita un crecimiento físico, intelectual y emocional en armonía. Bien sabemos que esta mirada es un tanto ideal, porque con frecuencia hay cambios de colegio, dificultades disciplinarias o de estudio, agresividad familiar, etcétera. Con los matices y salvedades que se quieran, sin embargo ella es en gran manera válida. Los alumnos viven, así, durante sus estudios básicos y medios en un clima de confianza; se sienten protegidos, con una suerte de techo protector que da calidez y seguridad.

Este techo desaparece de la noche a la mañana. Los jóvenes lo saben y se sienten desazonados. Los aguarda un mundo para ellos desconocido. La incertidumbre de ingresar a los estudios superiores deseados y a la institución preferida, aumenta esa desazón. La presión paterna y del medio ambiente -"tienes que seguir tal o cual carrera"- no contribuye precisamente a dar paz interior. ¡Y están los exámenes de fines de cuarto medio y los de la prueba de ingreso a la educación superior, los problemas de costo de los estudios universitarios, quizás el traslado de ciudad!

Junto a todo lo anterior está la alegría de concluir una etapa de la vida (esta última expresión es un tópico en los discursos de despedida 
y de graduación). Muchos alumnos han alcanzado una escolaridad que no alcanzaron sus padres, lo que los enorgullece y los compromete. La esperanza de continuar en mayor libertad estudios de prestigio y que son afines con sus gustos les parece un ideal increíble: "Ya no más matemáticas ni física", dicen algunos; "Qué felicidad, se acabó la gramática", dicen otros. Y todos piensan que será una dicha estudiar sólo lo que les gusta, sin inspectores, sin uniforme ni horas obligatorias de llegada o salida.

Así, a la postre, concurren sentimientos contradictorios de temor y esperanza, propios de una situación fronteriza en que hay término e inicio a la vez. Es una crisis que, bien llevada, implica posibilidades enormes de fortalecimiento, pero que es arriesgada, como toda crisis. Es el paso natural a la vez que difícil de la adolescencia a la primera juventud. Importa mucho que las universidades e institutos profesionales que van a recibir a jóvenes en esta situación sepan acogerlos haciéndose cargo de la realidad psicológica que ellos viven; que comprendan sin sobreproteger y que acojan adecuadamente, con el discurso requerido por personas necesitadas de afianzar su autoestima. No siempre las fiestas de "mechones" son el mejor encuentro con la Universidad; el inicio tardío y desordenado de las clases puede llevar a amenazadoras desilusiones. Las huelgas estudiantiles en el primer curso suelen inducir a peligrosas deserciones de las que -nos consta- es muy difícil reponerse.

\section{DESORIENTACIÓN VOCACIONAL}

Es un hecho que un porcentaje alto de los egresados de la enseñanza media no sabe con claridad lo que quieren seguir estudiando. Aunque en muchos liceos y colegios hay departamentos de psicoorientación que procuran orientar a los jóvenes para una acertada elección de carrera, buena parte escoge equivocadamente. Los ramos electivos consultados por el currículum oficial para tercero y cuarto medios son importantes al respecto; no sólo sirven para la enseñanza con alguna profundidad en determinadas materias, ya humanísticas, ya matemáticas y científicas, ya artísticas, sino sobre todo para conocer aptitudes y para reconocer posibles vocaciones. El alumno tiene la oportunidad de saber si realmente le gusta una materia u otra y si se 
siente "cómodo" con su estudio. Tratándose de uno de los pocos estudios de exploración real de los intereses potenciales que se ofrecen al alumno de media, deberían, por lo mismo, ser fortalecidos y aprovechados por los departamentos de psicoorientación en la tarea de aconsejarlo en la decisión vocacional. Lo mismo cabe decir de los talleres extracurriculares, que no pocos liceos y colegios ofrecen a los jóvenes. ¡Lástima que la escasez de tiempo impida dar a estos talleres un carácter curricular insertándolos en el plan normal de estudios!

Los bachilleratos ya implantados en diversas universidades son también un paliativo adecuado para esta situación. En ellos se escoge una zona de estudios -humanidades, ciencias naturales y matemáticas, por ejemplo- en las que se puedan descubrir vocaciones específicas en los dos o tres años de estos cursos de bachillerato, que tiene cierto carácter propedéutico. Es lo que se pretendió ya hace años con los Estudios Generales (Universidad Austral) o con los Institutos Básicos (Universidad de Concepción) y es lo que corresponde de alguna manera a los estudios de grado o colleges norteamericanos. Ojalá en nuestros bachilleratos las tareas de orientación tuvieran mayor desarrollo, de modo que los estudiantes encontraran en ellos apoyos que pueden serles fundamentales para su adecuada inserción en las asignaturas y escuelas que realmente correspondan a su vocación. Esto y una adecuada homologación y reconocimiento de materias impartidas en diversos institutos de una determinada universidad y aun de las que se estudian en diversas universidades, evitará deserciones o pérdidas innecesarias de tiempo.

En la misma línea es positivo que no pocos planteles de educación superior se hagan presentes en colegios y liceos con charlas y escritos acerca de la realidad de los estudios y carreras que ofrecen. Ojalá tales ofertas vayan más allá de un marketing, de suyo legítimo, y contribuyan objetivamente a superar la desorientación vocacional señalada. Visitas organizadas de alumnos de tercero y cuarto años medios a universidades e institutos profesionales pueden tener importancia en este aspecto.

En todo caso conviene acercar el final de los estudios de media con la realidad de los estudios superiores. Son niveles, claro, muy diversos. Pero es claro también que hay entre ellos un cierto continuo 
que debería ser tenido más en cuenta. Por una parte, la media -a pesar de su nombre no muy afortunado- tiene un sentido en sí misma o, más bien, debería tenerlo: implica un compacto de cuatro años de estudio de carácter enciclopédico, con bastante énfasis en lo humanístico: Ciencias Sociales, Comunicación y Lenguaje, Filosofía y Religión, un idioma extranjero, Artes Plásticas, Educación Musical; a su vez, Matemática y Ciencias Naturales son la contrapartida complementaria de las Humanidades. Educación Física y Técnicas Manuales terminan de configurar esta red de asignaturas que de ordinario comprende 40 horas semanales de clase. Lo dicho se refiere a los liceos humanístico-científicos. Los llamados técnicoprofesionales apuntan a la preparación de técnicos medios en muy diversas especialidades, desde gastronomía a electromecánica; en ellos, obviamente, la formación humanística es menor, lo que -ademásdificulta el ingreso de los alumnos a los estudios universitarios. Porque, a pesar del carácter de término que cabe reclamar con mayor justicia en este caso que en los liceos humanístico-científicos, los técnicoprofesionales preparan jóvenes que, aunque en proporción menor, también aspiran al tercer nivel de estudios. La relación que aquí echamos de menos es casi inexistente entre ellos y los establecimientos universitarios.

\section{PREPARACIÓN INTELECTUAL Y HUMANA}

Recuerdo que, años atrás, en un Congreso de la FIDE Secundaria, un rector universitario pedía a los directores de liceos y colegios allí presentes que le enviaran jóvenes con cabezas bien formadas, no con cabezas llenas. Si esto ocurría antes de la era de la computación y de Internet, cuando aún no se hablaba de globalización y recién aparecían los videos y la televisión, ¡con cuánto mayor énfasis ese rector y muchos otros harían la petición hoy día!

Cabezas bien formadas, capaces de pensar con lógica, de asociar con inteligencia, de observar atentamente y de inducir con corrección, de entender lo que leen y de expresarse adecuadamente, antes que atiborradas de datos y otros conocimientos pronto superados por el desarrollo científico y tecnológico, es lo que requieren no sólo las universidades, sino toda la sociedad y las propias personas luego de doce años de estudio. 
Por esto, dicho sea de paso, mi gran preocupación respecto de la malla curricular tan extensa en sus contenidos que presentan los recientes planes y programas de estudio oficiales. Hay en ellos un afán inadecuado de incluirlo todo, por ejemplo en Ciencias Sociales y en Lenguaje y Comunicación. Lejos de morigerarse, el enciclopedismo aumenta, con el consiguiente riesgo de que los profesores se sientan obligados a llenar más y más las cabezas y no tengan tiempo para jerarquizar los saberes, enseñar a disfrutarlos y a aprender con autonomía, a observar, a pensar lógicamente, a asociar y a integrar conocimientos, a leer adecuadamente y a escribir con corrección. No quedará tiempo para profundizar ni para acentuar elementos específicos de los proyectos educativos propios, lo que vendrá a uniformar lo que de suyo debe ser -más allá de los mínimos legítimosvariado y diverso, de acuerdo a la variedad y diversidad enormes de lo humano y geográfico de nuestro país.

Pero se requiere mucho más todavía; no basta con formar bien la cabeza. Los alumnos son personas y necesitan desarrollar su afectividad con equilibrio, su sensibilidad estética, su capacidad creativa; son seres sociales llamados a vivir en comunidades -familia, corporaciones, sociedad civil, iglesia- que deben conocer y respetar e incluso amar. Son hombres y mujeres que desean proyectarse más allá de lo puramente económico y que por su edad necesitan formularse proyectos de vida integrales, que satisfagan sus ansias de felicidad y sus eventuales decisiones de entrega generosa a causas grandes capaces de entusiasmarlos.

Muchos son los instrumentos, además de las clases propiamente tales, que emplean los establecimientos educacionales medios para atender tanta exigencia. Los centros de alumnos, la práctica deportiva, la inserción en grupos corales o de teatro, la formación de bandas musicales, los paseos de curso, etc., facilitan el conocimiento recíproco, el aprecio por la celebración propia y ajena, el compañerismo, la amistad misma. Misiones y trabajos voluntarios, scoutismo, visitas a hogares de ancianos o niños desvalidos y a hospitales, celebraciones eucarísticas, talleres, centros de reflexión, comunidades de oración y otros, despiertan y desarrollan inquietudes sociales y sentimientos de solidaridad, que están en la base de vidas éticamente orientadas y al servicio de esas causas grandes con que muchos adolescentes sueñan. 
¡Ojalá el ingreso a la Universidad no tronche tan valiosas iniciativas! Sabemos y apreciamos las altas exigencias académicas de una buena Universidad, sin las cuales la competencia profesional y las metas de la investigación no podrían ser satisfechas. Hay que estudiar y hay que estudiar mucho, pero sobre todo hay estudiar mejor. Como educador, no me resigno a que ese estudio sea incompatible con el sano ocio que permite la contemplación y facilita la creación artística, con las actividades generosas de bien social, con las celebraciones humanas y más que humanas nacidas del afán de alabar, agradecer o simplemente recordar a quienes merecen alabanzas, gratitud o mero recuerdo.

Falta hace que, para lograr éstas y otras metas similares, la relación entre los niveles segundo y tercero de la educación nacional sea más estrecha. ¿Por qué no establecer comisiones mixtas, no sólo de autoridades directivas sino también de profesores y alumnos, que aborden el continuo de nuestra tarea educacional y propongan medidas concretas que faciliten el paso de un nivel a otro?

Cuanto se haga en este sentido será bienvenido. 